\title{
In vitro response of human peripheral blood mononuclear cells to AISI 316L austenitic stainless steel subjected to nitriding and collagen coating treatments
}

\author{
Maria Stio • Maria Martinesi - Cristina Treves • \\ Francesca Borgioli
}

Received: 7 August 2014/ Accepted: 27 November 2014/Published online: 6 February 2015

(C) Springer Science+Business Media New York 2015

\begin{abstract}
Surface modification treatments can be used to improve the biocompatibility of austenitic stainless steels. In the present research two different modifications of AISI 316L stainless steel were considered, low temperature nitriding and collagen-I coating, applied as single treatment or in conjunction. Low temperature nitriding produced modified surface layers consisting mainly of $\mathrm{S}$ phase, which enhanced corrosion resistance in PBS solution. Biocompatibility was assessed using human peripheral blood mononuclear cells (PBMC) in culture. Proliferation, lactate dehydrogenase (LDH) levels, release of cytokines (TNF- $\alpha$, IL-1 $\beta$, IL-12, IL-10), secretion of metalloproteinase (MMP)-9 and its inhibitor TIMP-1, and the gelatinolytic activity of MMP-9 were determined. While the 48-h incubation of PBMC with all the sample types did not negatively influence cell proliferation, LDH and MMP-9 levels, suggesting therefore a good biocompatibility, the release of the pro-inflammatory cytokines was always remarkable when compared to that of control cells. However, in the presence of the nitrided and collagen coated samples, the release of the pro-inflammatory cytokine IL- $1 \beta$ decreased, while that of the anti-inflammatory cytokine IL-10 increased, in comparison with the untreated AISI 316L samples. Our results suggest that some biological parameters were ameliorated by these surface treatments of AISI 316L.
\end{abstract}

M. Stio · M. Martinesi - C. Treves

Department of Biomedical, Experimental and Clinical Sciences 'Mario Serio', Section of Biochemical Sciences, University of Florence, Viale Morgagni 50, 50134 Florence, Italy

F. Borgioli $(\square)$

Department of Industrial Engineering (DIEF), University of

Florence, Via S. Marta 3, 50139 Florence, Italy

e-mail: francesca.borgioli@unifi.it

\section{Introduction}

The biological responses to metallic implanted materials, such as austenitic stainless steels, represent an important field of research, since the effects of metal release into body fluids may negatively influence biocompatibility [1]. The metallic corrosion products are often associated with many adverse conditions, as allergic responses [2], degradative processes of the implant [3], and, in general, with biocompatibility problems [4], also related to the activation of the coagulation cascade. Austenitic stainless steels have a good corrosion resistance, which, however, decreases in contact with body fluids [5]. Therefore, it would be necessary to modify the surface of the metallic implants, in order to obtain a better resistance to corrosion and a better biocompatibility. Among the surface treatment techniques, surface alloying with nitrogen by means of low temperature nitriding improves corrosion resistance of austenitic stainless steels in chloride-ion containing solutions, as body fluids are [6-8]. When treatment temperatures lower than $450{ }^{\circ} \mathrm{C}$ are used, nitrogen is retained in a supersaturated solid solution, known as expanded austenite or S phase [9], and the precipitation of chromium nitrides, which usually decreases corrosion resistance, is avoided. Moreover, this treatment maintains, or even increases, the biocompatibility of austenitic stainless steels [7, 10, 11]. Another adopted strategy is the coating of medical devices with more biocompatible materials. Hauser et al. [12] improved the biocompatibility of titanium and stainless steel alloys by plasma mediated collagen-Icoating. As reported in an our previous paper [13], collagen coating can be also promoted by low temperature nitriding treatment of AISI 316L austenitic stainless steel, and this collagen protection may be favourable for endothelial cell proliferation and for the control of metalloproteinase 
(MMP)-2 release. Collagen, the major component of extracellular matrix, shows high conformational stability, little inflammatory reaction and good cytocompatibility [14]. This protein is also involved in many biological functions, as cell attachment and tissue regeneration, and, for these reasons, it has been used to modify the surface of medical devices in order to induce cell-material interactions. Since collagen is known to be thrombogenic, by causing blood coagulation and platelet activation, collagen coating alone is not usually considered good for blood contacting devices. However, the ability of collagen to promote a rapid endothelial cell attachment may reduce its adverse effects for those implants which may come in contact with blood.

Blood cells have been widely employed to test biocompatibility, since monocytes and macrophages recruited to material-tissue interface play a fundamental role in the inflammatory response to the material itself $[15,16]$. In the immune response, peripheral blood mononuclear cells (PBMC) produce a wide array of cytokines. Nonstimulated human PBMC produce Interleukin (IL)-6, Tumor Necrosis Factor (TNF)- $\alpha$, IL-10, and also IL-1 $\beta$, while, when stimulated by lipopolysaccharide (LPS), they increase the net production of IL-1 $\beta$ and TNF- $\alpha$ [17]. More recently, it has been reported that monocytes, PBMC, and THP-1 cells exhibit different cytokine expression patterns following LPS stimulation [18]. Also a biomaterial may induce the activation of macrophages, which, in an attempt to phagocytose it, secrete many inflammatory mediators, such as cytokines. Chang et al. [19] investigated cytokines, chemokines, and extracellular matrix (ECM) proteins produced by lymphocytes and macrophages in response to biomaterial surfaces. These authors hypothesized that the production of inflammatory molecules from lymphocytes and macrophages in response to the contact with biomaterials could be modulated by the biomaterial surface chemistry. Upon activation, macrophages secrete not only pro-inflammatory cytokines, but also anti-inflammatory molecules, as IL-10. IL-10 inhibits the synthesis of the inflammatory cytokines, and thus it controls the inflammatory response. Therefore, when blood cells are used for biocompatibility studies, it is important to consider also the production and the behaviour of different cytokines.

In order to understand how macrophages can influence ECM remodelling, Jones et al. [20] have studied the differential secretion of metalloproteinases (MMPs) and of their inhibitors (tissue inhibitors of metalloproteinases, TIMPs) by adherent macrophages and foreign body giant cells. MMPs are proteolytic proteins that hydrolyze components of ECM and degrade the damaged ECM, facilitating cellular migration through the matrix. MMPs can promote the release of growth factors and cytokines bound on cell surface, and directly influence the composition of
ECM. MMPs play therefore important roles not only in many physiological processes, but also in pathological ones, including inflammation. It has been demonstrated a relation between MMPs and the production of pro-inflammatory cytokines. In fact, MMPs regulate the activity of cytokines and growth factors such as TNF- $\alpha$ and IL-1 $\beta$, by cleaving the components of the ECM, that sequester them [21, 22]. On the other hand, the expression of MMPs is up- or down-regulated by numerous factors, including cytokines. Biomaterial-adherent macrophages produce MMP-9, TIMP-1 and TIMP-2, and they may modulate not only the surrounding ECM, but also the cellular behaviour, by secreting abnormal amounts of MMPs and TIMPs [20].

The aim of our research was to study if low temperature nitriding and collagen-I coating procedure can be favourably used to maintain or even increase the biocompatibility of AISI 316L austenitic stainless steel. Human PBMC in culture were used as experimental model. The cells were incubated in vitro with AISI 316L samples untreated or subjected to nitriding and/or collagen coating. Cell proliferation, lactate dehydrogenase $(\mathrm{LDH})$ release, and the production of three pro-inflammatory cytokines (TNF- $\alpha$, IL-1 $\beta$, IL-12) and of an anti-inflammatory one (IL-10) were determined. Among the pro-inflammatory cytokines, TNF- $\alpha$ may be considered a marker of cellular activity, as it represents one of the primary stimuli in the inflammatory cascade [23]. Moreover, TNF- $\alpha$ and IL-1 $\beta$ are important signalling molecules involved in directing the response to foreign materials, and their up-regulation is a measure of inflammation [24]. The levels of MMP-9 and its inhibitor TIMP-1 were also evaluated.

\section{Materials and methods}

\subsection{Preparation of AISI 316L samples}

Prismatic samples $(40 \times 17 \times 0.7 \mathrm{~mm})$ of AISI $316 \mathrm{~L}$ austenitic stainless steel were cut from cold rolled, annealed and pickled plates, and they were ground and polished up to $6-\mu \mathrm{m}$ diamond suspension. The chemical composition of the steel was the following (in wt \%): 0.029 C, 16.6 Cr, 10.3 Ni, 2.01 Mo, 0.90 Mn, 0.34 Si, 0.001 S, $0.029 \mathrm{P}$.

Low temperature nitriding treatment was performed by means of the glow-discharge technique in a laboratory plasma equipment, previously described [25]. The samples were heated up to about $330{ }^{\circ} \mathrm{C}$ by means of cathodic sputtering, carried out at $130 \mathrm{~Pa}$ with 80 vol. $\% \mathrm{~N}_{2}$ and 20 vol. $\% \mathrm{H}_{2}$; after this sputtering step, the pressure and the temperature were increased up to their nominal values. The nitriding treatment was performed at $400{ }^{\circ} \mathrm{C}$, at a pressure of $500 \mathrm{~Pa}$, for $5 \mathrm{~h}$, using a gas composition of $80 \mathrm{vol} . \% \mathrm{~N}_{2}$ 
and $20 \mathrm{vol} . \% \mathrm{H}_{2}$. The current density was $1.6 \mathrm{~mA} / \mathrm{cm}^{2}$ and the voltage drop was $195 \mathrm{~V}$.

\subsection{Sample characterization}

The microstructure of untreated and nitrided samples was analysed by optical and scanning electron (SEM) microscopy and energy dispersion spectroscopy (EDS) techniques. The phases present in the surface layers were identified by means of X-ray diffraction analysis $(\mathrm{Cu} \mathrm{K \alpha}$ radiation). Diffraction patterns were collected both in Bragg-Brentano configuration and with a $10^{\circ}$-constant incident angle; in this latter configuration, the mean penetration depth (i.e., the depth at which the intensity drops by a factor of $e$ ) was $0.6 \mu \mathrm{m}$.

Roughness measurements were carried out on the surface of untreated and nitrided samples using a stylus profilometer tester. The measurements were performed with a $2-\mu \mathrm{m}$ radius stylus with a $1-\mathrm{mN}$ contact force; the cut-off length was $0.25 \mathrm{~mm}$. Ten measurements were taken at different locations on each sample. The average surface roughness $\mathrm{Ra}$ (arithmetical mean deviation of the roughness profile from the mean line) and the maximum height of profile $\mathrm{Rz}$ (sum of the largest profile peak height and largest profile valley depth within a sampling length, according to EN ISO 4287-2009 norm) were recorded.

Corrosion resistance of untreated and nitrided samples was studied in aerated phosphate-buffered saline (PBS) solution at room temperature. PBS (Sigma Life Science) contained $137 \mathrm{mM} \mathrm{NaCl}, 2.7 \mathrm{mM} \mathrm{KCl}, 4.3 \mathrm{mM} \mathrm{NaH} 2$


using a three-electrode electrochemical flat cell equipped with $\mathrm{Ag} / \mathrm{AgCl}(3.5 \mathrm{M} \mathrm{KCl})$ reference electrode and a platinum grid as counterelectrode. The sample surface area exposed to the electrolyte was $1 \mathrm{~cm}^{2}$.

Potentiodynamic polarisation measurements were performed at a sweep rate of $0.3 \mathrm{mV} / \mathrm{s}$ after a delay period of $20 \mathrm{~h}$. Three corrosion tests for each sample type were carried out in order to assess the result.

In order to evaluate the degradation due to corrosion phenomena, a coulimetric zone analysis was performed, following the guidelines proposed by Reclaru et al. [26, 27]. The method consists of dividing the anodic polarisation curves into two distinct zones: the first zone (zone I) ranges from the corrosion potential up to $+450 \mathrm{mV}(\mathrm{Ag} /$ $\mathrm{AgCl}$ ), and the second zone (zone II) from +450 to $+800 \mathrm{mV}(\mathrm{Ag} / \mathrm{AgCl})$. The limit of zone I was chosen because alloys in human body may be exposed to potentials up to $+450 \mathrm{mV}(\mathrm{Ag} / \mathrm{AgCl})[28,29]$. The upper limit of zone II $(+800 \mathrm{mV}(\mathrm{Ag} / \mathrm{AgCl}))$ was chosen taking into account that, for higher potential values, water becomes unstable and tends to decompose evolving oxygen [29]. The potential range of zone I may occur in clinical conditions, while higher potentials, as those in zone II, may occur in exceptional situations. For the analysis, current density values of the polarisation curves were integrated for each zone, taking into account that:

$\operatorname{potential}(\mathrm{mV}) / \mathrm{scan} \operatorname{rate}(\mathrm{mV} / \mathrm{s})=\operatorname{time}(\mathrm{s})$

The integration was performed using the program Echem Analyst (Gamry). The results were expressed as charge for unit surface $\left(\mu \mathrm{C} / \mathrm{cm}^{2}\right)$.

\subsection{Sterilization}

For the sterilization procedure, the untreated and nitrided AISI 316L samples (previously cut to obtain $1 \mathrm{~cm}^{2}$ each) were first rinsed with sterilized deionized water, then rinsed one time with $100 \%$ ethanol $(30 \mathrm{~min})$, and repeatedly washed with sterilized deionized water. The samples were then exposed overnight to UV irradiation.

\subsection{Collagen coating procedure}

Half of the samples (untreated or nitrided) were collagen coated, following the guidelines of Hauser et al. [12]. Collagen type I from rat tail $4 \mathrm{mg} / \mathrm{ml}$ in $20 \mathrm{mM}$ acetic acid (BD Biosciences, Bedford, MA) was diluted 1:8 with sterilized deionized water to $0.5 \mathrm{mg} / \mathrm{ml}$ end concentration. The samples were incubated with $0.5 \mathrm{ml}$ diluted collagen $/ \mathrm{cm}^{2}$ for $24 \mathrm{~h}$ at $4{ }^{\circ} \mathrm{C}$ under sterile conditions. Afterwards the supernatant was discarded and the samples were incubated with $0.5 \mathrm{ml}$ diluted collagen $/ \mathrm{cm}^{2}$ for another $48 \mathrm{~h}$ at $37{ }^{\circ} \mathrm{C}$ under sterile conditions. After drying, the samples were rinsed with sterilized deionized water to eliminate the non adherent collagen. The samples, which were not collagen coated, were incubated with acetic acid used at the same concentration present in the collagen solution and they were subjected to the same procedure followed for the collagen coating. The untreated stainless steel samples were indicated as $\mathrm{S}$, the nitrided ones as $\mathrm{T}$. When these samples were collagen coated, they were indicated as SC and TC, respectively.

\subsection{Cell cultures}

Human peripheral blood mononuclear cells (PBMC) were obtained from healthy volunteer subjects by density gradient (1.077) centrifugation (30 $\mathrm{min}$ at $400 \times g$ ) of heparinized venous blood (different blood samples of $10 \mathrm{ml}$ each) diluted 1:2 with Dulbecco's Phosphate Buffered Saline (PBS) on Ficoll-Paque (research grade, Amersham Pharmacia Biotech.). About $95 \%$ mononuclear cells at the interface, containing PBMC, was collected and washed twice with PBS. PBMC viability, checked by measuring Trypan blue dye exclusion, was $>90 \%$. PBMC were cultured in RPMI 1640 supplemented with $25 \mathrm{mM}$ Hepes, 
$10 \%$ (v/v) heat inactivated Fetal Bovine Serum (FBS), $60 \mathrm{mg} / \mathrm{ml}(100 \mathrm{U} / \mathrm{ml})$ penicillin, $100 \mathrm{mg} / \mathrm{ml}$ streptomycin, $0.29 \mathrm{~g} / \mathrm{l}$ L-glutamine. PBS, Trypan Blue solution, RPMI 1640, Hepes, FBS, antibiotics and L-glutamine were from Sigma Life Science. PBMC were divided in five groups and were seeded in each well $\left(3.8 \mathrm{~cm}^{2}\right)$ at a density of $1 \times 10^{6}$ cells/group: control group received only complete culture medium; four groups were maintained in direct contact with the four sample types (one sample type for each group) for $48 \mathrm{~h}$. To all groups $2 \mu \mathrm{g} / \mathrm{ml}$ phytohemagglutinin (PHA) (Sigma Life Science) were added. Cultures were maintained at $37{ }^{\circ} \mathrm{C}$ in humidified atmosphere containing $5 \% \mathrm{CO}_{2}$. When PBMC were collected, at the end of the incubation times, the adherent monocytes were scraped and added to the non-adherent cells. Culture media were collected, spun for $10 \mathrm{~min}$ at 2,000 rpm and immediately used for LDH assay or stored at $-20{ }^{\circ} \mathrm{C}$ for the determination of cytokines, MMP-9 and TIMP-1.

\subsection{Proliferation assay}

The WST-8 Cell Proliferation Assay Kit (Cayman Chemical Company) was used to assess cell proliferation and viability. The assay is based on the extracellular reduction of WST-8 by NADH produced in the mitochondria via trans-plasma membrane electron transport and an electron mediator. WST-8 produces a water-soluble formazan which dissolves directly into the culture medium, eliminating the need for an additional solubilization step. The detection sensitivity is higher than that for other tetrazolium salts. The formazan dye produced by viable cells was quantified by measuring the absorbance of the dye solution at $450 \mathrm{~nm}$. Background absorbance of the culture medium without cells was subtracted. Proliferation was expressed as per cent of that registered in control cultures (PBMC maintained in the presence of the complete culture medium alone).

\subsection{Lactate dehydrogenase assay}

The LDH Cytotoxicity Assay Kit (Cayman Chemical Company) was used to assess the amount of LDH released by PBMC into the culture medium as a result of cytotoxicity, after 48-h incubation of the cells with the complete culture medium alone (control PBMC) or with the samples under study. This kit uses a coupled two-step reaction. In the first step, LDH catalyzes the reduction of $\mathrm{NAD}^{+}$to NADH and $\mathrm{H}^{+}$by oxidation of lactate to pyruvate. In the second step of the reaction, diaphorase uses $\mathrm{NADH}$ and $\mathrm{H}^{+}$to catalyze the reduction of a tetrazolium salt to formazan, which absorbs at $490 \mathrm{~nm}$. LDH activity was expressed as per cent of that registered in control cultures (PBMC maintained in the presence of the complete culture medium alone). Control PBMC released
$9.25 \mu \mathrm{U} \mathrm{LDH} / \mathrm{ml}$, and the data were calculated setting those of control equal to 100 .

\subsection{Measurement of cytokines, MMP-9 and TIMP-1}

For measurement of cytokines, MMP-9 and TIMP-1 in the culture media of PBMC after 48-h incubation with the complete culture medium alone (control PBMC) or with the samples under study, ELISA kits (Boster Biological Technology Co., Ltd.) were used according to the instructions provided by the manufacturer. The detection limits were $15.6-1,000 \mathrm{pg} / \mathrm{ml}$ for TNF- $\alpha, 1.56-100 \mathrm{pg} / \mathrm{ml}$ for IL-1 $\beta, 31.2-2,000 \mathrm{pg} / \mathrm{ml}$ for IL-12, 7.8-500 pg/ml for IL-10, $156-10,000 \mathrm{pg} / \mathrm{ml}$ for MMP-9, $156-1,000 \mathrm{pg} / \mathrm{ml}$ for TIMP-1. The levels of cytokines, MMP-9 and TIMP-1 were normalized with basis on cell proliferation and expressed as $\mathrm{pg} / \mathrm{ml}$.

\subsection{Zymography}

MMP-9 gelatinase activity was visualised by zymography. Briefly, SDS polyacrylamide gels $(8 \%)$ containing $0.1 \%$ gelatine were overlaid with $4 \%$ stacking gels. Samples of culture media were mixed (10:1 volume) with a sample buffer consisting of $50 \mathrm{mM}$ Tris- $\mathrm{HCl}$, pH 6.8, $2 \%$ SDS, $20 \%$ glycerol, $0.03 \%$ bromophenol blue. After loading the samples, electrophoresis was carried out at $125 \mathrm{~V}$ for $2 \mathrm{~h}$. After electrophoresis, the gels were soaked in $2.5 \%$ Triton X-100 on a shaker for $1 \mathrm{~h}$, at room temperature, changing the solution after $30 \mathrm{~min}$, to eliminate SDS. The gels were then equilibrated for $30 \mathrm{~min}$ with the digestion buffer (50 mM Tris- $\mathrm{HCl}$, pH 7.5, $5 \mathrm{mM} \mathrm{CaCl}_{2}, 200 \mathrm{mM}$ $\mathrm{NaCl})$ at room temperature with gentle agitation, then replaced with fresh digestion buffer and incubated at $37{ }^{\circ} \mathrm{C}$ overnight. The gels were then stained for $1-2 \mathrm{~h}$ with $0.5 \%$ Coomassie Brilliant Blue in $30 \%$ methanol and $10 \%$ acetic acid and destained with $30 \%$ methanol and $10 \%$ acetic acid, after which clear bands of digested gelatine were clearly visible. The gels were scanned by Chemi-Doc (Bio-Rad), utilizing the Quantity One program (Bio-Rad). The densitometric values were normalized with basis on cell proliferation.

\subsection{Statistical methods}

Statistical significance was determined by either one-way analysis of variance (ANOVA), followed by Bonferroni $t$ test or by Student's $t$ test. One-way ANOVA was used to determine significance among groups, after which the modified $t$ test with the Bonferroni correction was used for comparison between individual groups. Differences were considered significant at $P<0.05$. 
Fig. 1 Surface morphology of untreated (a) and nitrided (b) AISI 316L stainless steel samples
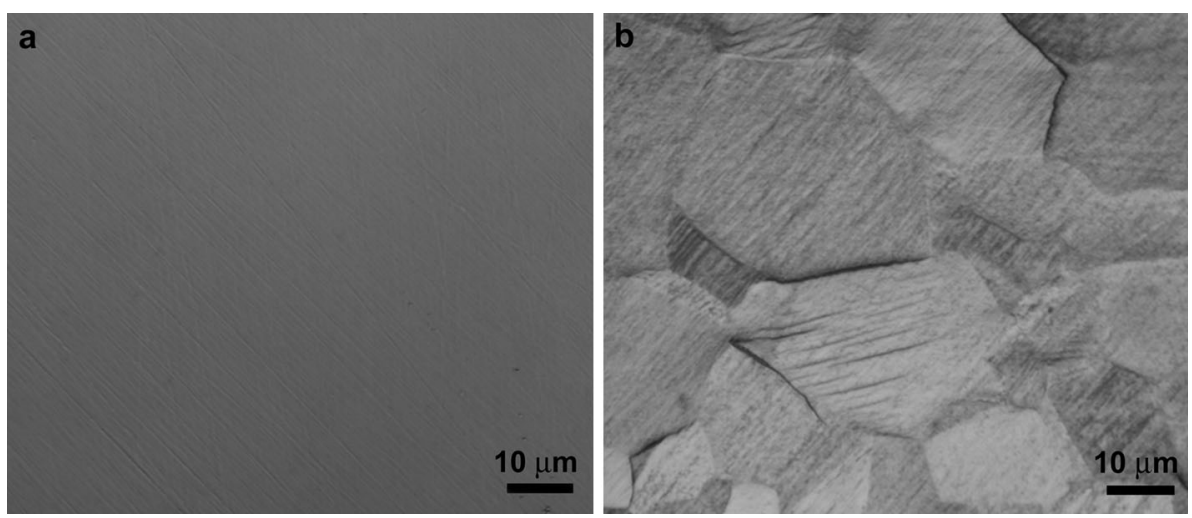

\section{Results}

3.1 Morphology and microstructure of the nitrided samples

The surface of untreated AISI 316L samples shows the presence of shallow grooves, due to the grinding and polishing procedures (Fig. 1a). The roughness is fairly low, with $\mathrm{Ra}=0.006 \pm 0.003 \mu \mathrm{m} \quad$ and $\mathrm{Rz}=0.039 \pm$ $0.006 \mu \mathrm{m}$. X-ray diffraction analysis shows that, besides $\gamma$ $\mathrm{Fe}$ (f.c.c.) peaks, very small peaks of $\alpha$-Fe (b.c.c.) are also present (Fig. 2a). These peaks overlap the peaks of b.c.t. $\alpha$ ' martensite, which may also form during grinding and polishing.

The nitriding treatment modifies surface microstructure: ion bombardment during sputtering step and nitriding causes an etching which outlines the austenitic microstructure (Fig. 1b). Moreover, slip steps and high reliefs at grain boundaries are observed. The modification of surface microstructure causes an increase of surface roughness, with $\mathrm{Ra}=0.058 \pm 0.005 \mu \mathrm{m}$ and $\mathrm{Rz}=0.44 \pm 0.03 \mu \mathrm{m}$. X-ray diffraction analysis shows that the modified surface layers consist mainly of S phase, the supersaturated solid solution of nitrogen in the expanded and distorted f.c.c. lattice (Fig. 2b). The peaks characteristic of the nitrogen induced h.c.p. martensite, $\varepsilon_{N}$, were also detected. As also shown in an our previous paper [13], using these treatment parameters the modified surface layers are homogeneous and they are about $7-\mu \mathrm{m}$ thick as a whole.

\subsection{Corrosion behaviour}

Polarisation curves representative of the corrosion behaviour of untreated and nitrided samples tested in PBS are shown in Fig. 3; the average values of the corrosion potential, anodic current in the passive branch and charge for unit surface relative to the two chosen potential ranges (zones I and II) are reported in Table 1. Both sample types have a corrosion behaviour characteristic of a passive

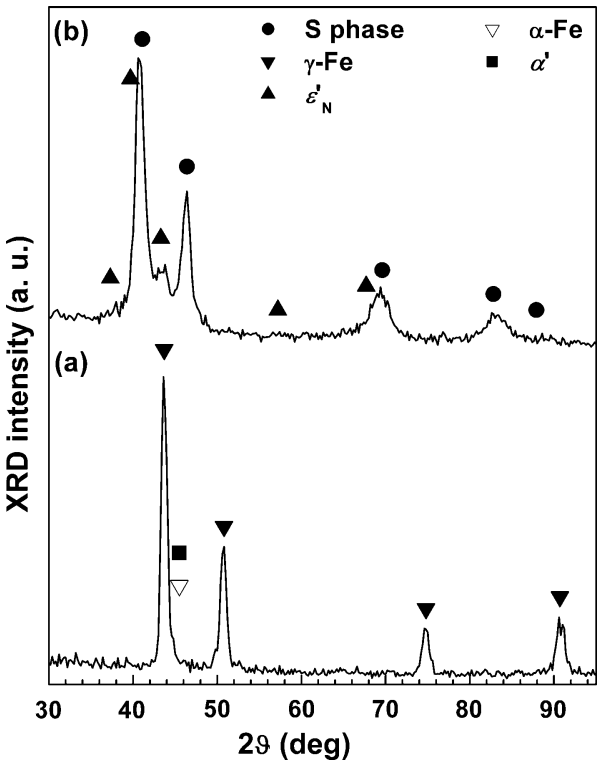

Fig. 2 X-ray diffraction patterns of untreated $(a)$ and nitrided (b) AISI $316 \mathrm{~L}$ stainless steel samples (configuration: $10^{\circ}$-incident angle)

material, with very low anodic currents in the passive branch. However, nitrided samples have corrosion potential values markedly higher than those of untreated AISI 316L, and their anodic current values are lower, suggesting a higher corrosion resistance. Coulimetric zone analysis is in accordance with potentiodynamic results: the charge values of both zones I and II are significantly lower for nitrided AISI 316L samples in comparison with the untreated ones.

\section{3 $\mathrm{PBMC}$ proliferation and $\mathrm{LDH}$ release in the culture medium}

The influence of untreated and nitrided AISI 316L samples, subjected or not to collagen coating, on PBMC proliferation and on the release of LDH in the culture medium, after 48-h incubation, was investigated (Fig. 4). PBMC maintained in the presence of the complete culture medium alone were used as control and indicated as PBMC. While 
PBMC proliferation, registered in the presence of the samples, does not show any significant change in comparison with control cells, a slight but significant increase in cell proliferation is registered in the presence of nitrided and collagen coated samples (TC) when compared to the untreated ones $(\mathrm{S})$.

$\mathrm{LDH}$ is a soluble enzyme present in the cytosol, which is released into the surrounding culture medium upon cell damage or lysis. Therefore, LDH activity in the culture medium can be used as an indicator of cell membrane integrity, representing a measurement of cytotoxicity. As observed in the proliferation studies, also LDH levels are very similar each other. A slight but significant increase in $\mathrm{LDH}$ release is registered in the presence of the collagen coated samples (SC and TC) in comparison with control PBMC, and in the presence of TC samples in comparison with $\mathrm{S}$ samples.

\subsection{Cytokine (TNF- $\alpha$, IL-1 $\beta$, IL-12, IL-10) release in the culture medium}

In order to verify whether the 48-h contact with the samples may affect the release of cytokines by PBMC, the levels of three pro-inflammatory cytokines (TNF- $\alpha$, IL-1 $\beta$, IL-12) and of an anti-inflammatory one (IL-10) were assayed in the culture medium. PBMC maintained in the

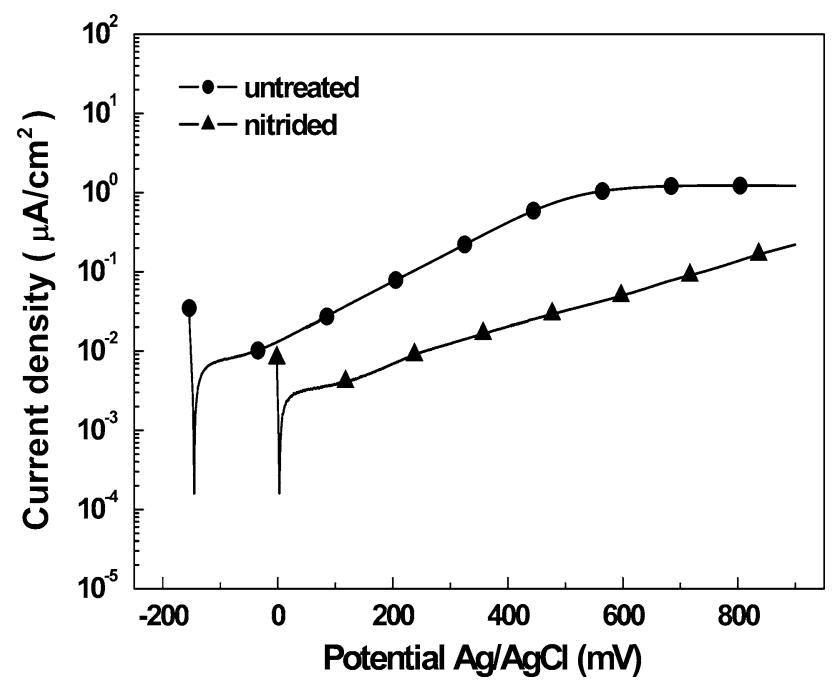

Fig. 3 Polarisation curves of untreated and nitrided AISI 316L stainless steel samples (solution: PBS, aerated)

Table 1 Average corrosion potential, $\mathrm{E}_{\mathrm{c}}$, anodic current density in the passive branch, $\mathrm{i}_{\mathrm{p}}$, charge for unit surface of zone I (from Ec to $+450 \mathrm{mV}(\mathrm{Ag} / \mathrm{AgCl})$ ), $\mathrm{Q}_{\mathrm{I}}$, and of zone II (from +450 to $+800 \mathrm{mV}$ presence of the complete culture medium alone were used as control and indicated as PBMC. Figure 5a depicts the levels of TNF- $\alpha$, which always increase when PBMC were cultured in the presence of the samples in comparison with control cells. The levels of IL- $1 \beta$ are very low in the culture medium of control PBMC, as expected, but they noteworthy increase in the presence of all the samples, reaching the highest value in the presence of $S$ samples (Fig. 5b). A significant decrease in IL-1 $\beta$ levels is observed, when the collagen coated samples are compared with the non collagen coated ones, even if the values remain high in comparison with those of control PBMC. Also the levels of the other pro-inflammatory cytokine, IL-12, are low in the culture medium of control PBMC and remarkably increase in the presence of all the samples (Fig. 5c), but, differently from what observed for IL-1 $\beta$, they don't tend to decrease in the presence of the collagen coated samples ( $\mathrm{SC}$ and $\mathrm{TC}$ ). The highest value is registered in the presence of SC. Figure $5 \mathrm{~d}$ reports the results obtained, when the levels of the anti-inflammatory cytokine IL-10 were assayed in the culture medium of PBMC. Interestingly, in the presence of the nitrided samples,

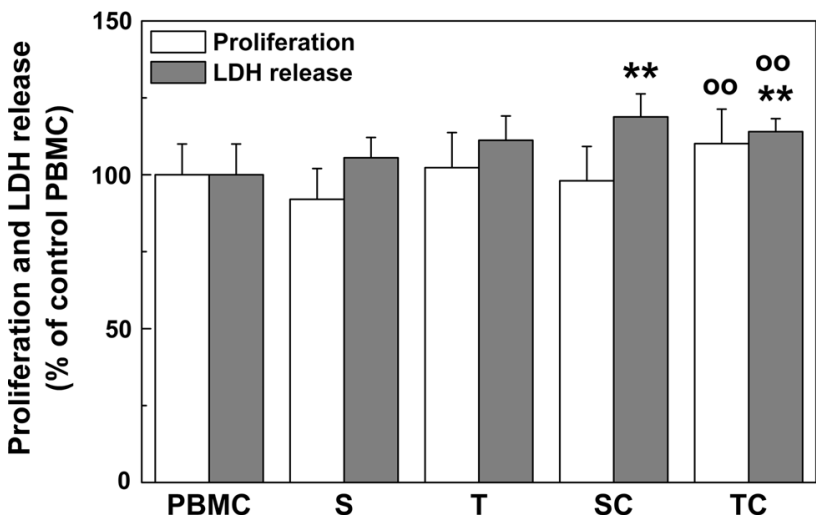

Fig. 4 Effect of AISI 316L stainless steel sample types on PBMC proliferation and LDH release in the culture medium. Cells were maintained in the presence of the complete culture medium alone (PBMC) or put in contact for $48 \mathrm{~h}$ with samples ( $S$ untreated stainless steel; $T$ nitrided stainless steel; $S C$ untreated, collagen coated stainless steel; TC nitrided, collagen coated stainless steel). Data are given relative to the values obtained in the presence of control cells (PBMC), set equal to 100. Each value represents the mean $\pm \mathrm{SD}$ of six separate experiments, each performed in duplicate. Control PBMC released $9.25 \pm 0.35 \mu \mathrm{U} \mathrm{LDH} / \mathrm{ml}$. ** $P<0.05$ (in comparison with $\mathrm{PBMC}$ ); ${ }^{\circ} \mathrm{P}<0.05$ (in comparison with $\mathrm{S}$ )

$(\mathrm{Ag} / \mathrm{AgCl})), \mathrm{Q}_{\mathrm{II}}$, for untreated and nitrided AISI 316L stainless steel samples (solution: PBS; aerated)

\begin{tabular}{lcccr}
\hline Sample type & $\mathrm{E}_{\mathrm{c}}(\mathrm{mV}(\mathrm{Ag} / \mathrm{AgCl}))$ & $\mathrm{i}_{\mathrm{p}}\left(\mu \mathrm{A} / \mathrm{cm}^{2}\right)$ & $\mathrm{Q}_{\mathrm{I}}\left(\mu \mathrm{C} / \mathrm{cm}^{2}\right)$ & $\mathrm{Q}_{\mathrm{II}}\left(\mu \mathrm{C} / \mathrm{cm}^{2}\right)$ \\
\hline Untreated & $-156 \pm 10$ & $0.06 \pm 0.01$ & $18 \pm 2$ & $100 \pm 10$ \\
Nitrided & $-10 \pm 10$ & $0.59 \pm 0.04$ & $407 \pm 40$ & $1,227 \pm 45$ \\
\hline
\end{tabular}



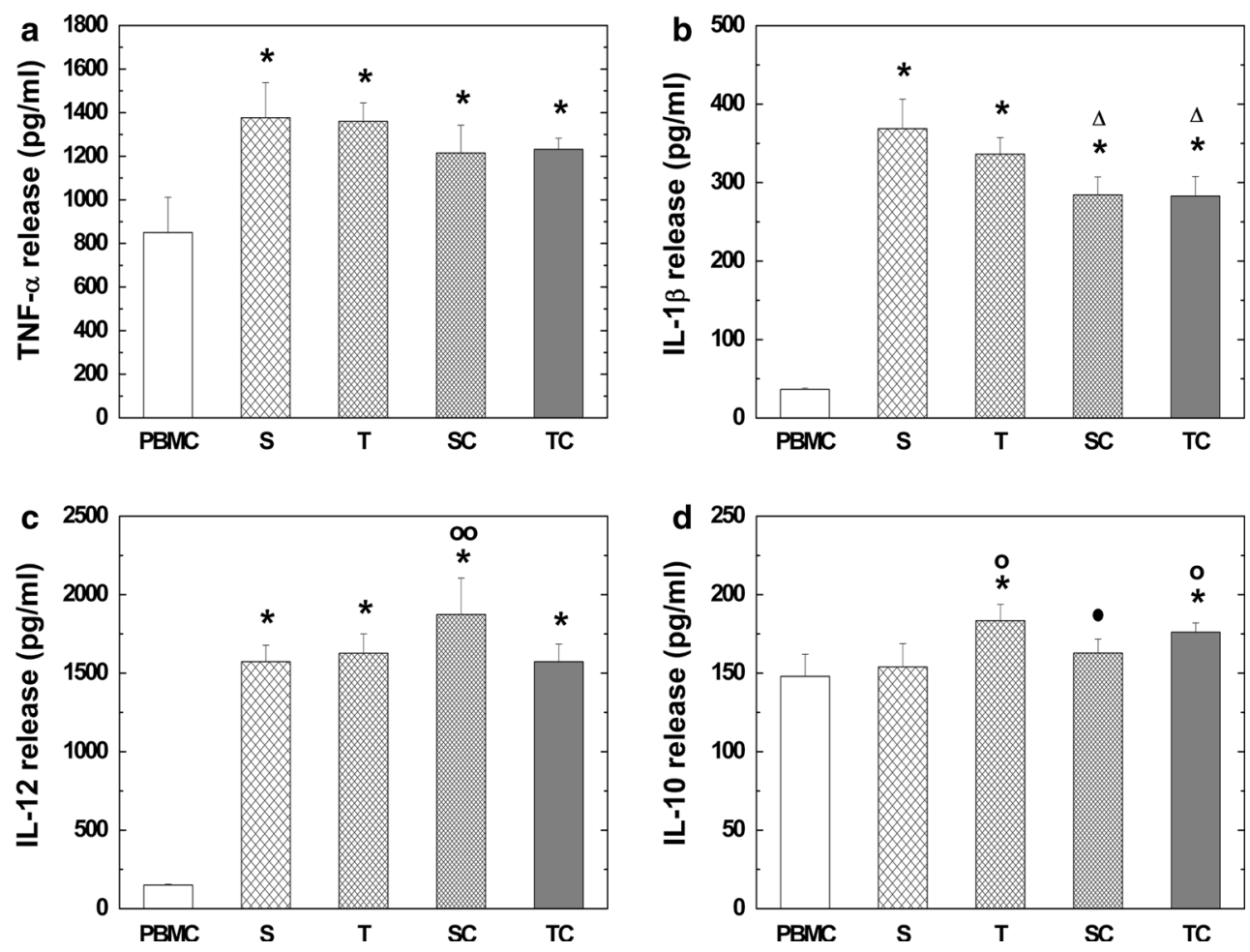

Fig. 5 Effect of AISI 316L stainless steel sample types on the release of cytokines in the culture medium by PBMC (a TNF- $\alpha$; b IL- $1 \beta$; c IL-12; d IL-10). Cells were maintained in the presence of the complete culture medium alone (PBMC) or put in contact for $48 \mathrm{~h}$ with samples ( $S$ untreated stainless steel; $T$ nitrided stainless steel; $S C$ untreated, collagen coated stainless steel; $T C$ nitrided, collagen coated

stainless steel). Data, normalized with basis on cell proliferation, are expressed as $\mathrm{pg} / \mathrm{ml}$. Each value represents the mean $\pm \mathrm{SD}$ of six separate experiments, each performed in duplicate. ${ }^{*} P<0.01$ (in comparison with PBMC); ${ }^{\Delta} P<0.01$ (in comparison with $\mathrm{S}$ and $\mathrm{T}$ ); ${ }^{\circ} P<0.01$ (in comparison with $\mathrm{S}$ ); ${ }^{\circ \circ} P<0.05$ (in comparison with $\mathrm{S}$ and TC); ${ }^{\bullet} P<0.01$ (in comparison with $\mathrm{T}$ )

collagen coated or not ( $\mathrm{T}$ and TC), the levels of IL-10 are higher in comparison with both control PBMC and the untreated samples (S).

\subsection{MMP-9 and TIMP-1 release in the culture medium}

MMP-9 is a member of the large family of enzymes, which act on the cell matrix. MMP-9, constitutively expressed also by PBMC, plays a key role in the pathogenesis of the inflammatory diseases. Biological activities of MMPs are strictly regulated by specific tissutal inhibitors, TIMPs. TIMP-1 is the main inhibitor of MMP-9. In Fig. 6 the influence of untreated and nitrided AISI 316L samples, subjected or not to collagen coating, on the release of MMP-9 and TIMP-1 in the culture medium by PBMC, after 48-h incubation, is depicted. PBMC maintained in the presence of the complete culture medium alone were used as control and indicated as PBMC. With the exception of S samples, in the presence of all the other samples the release of MMP-9 is always lower in comparison with control PBMC. A lower release of TIMP-1 in comparison with control PBMC is registered in the presence of all the

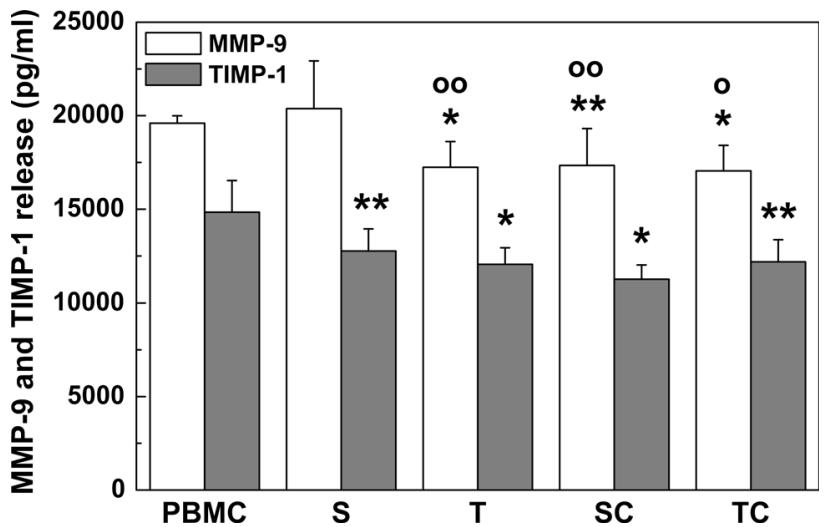

Fig. 6 Effect of AISI 316L stainless steel sample types on the release of MMP-9 and TIMP-1 in the culture medium by PBMC. Cells were maintained in the presence of the complete culture medium alone (PBMC) or put in contact for $48 \mathrm{~h}$ with samples ( $S$ untreated stainless steel; $T$ nitrided stainless steel; $S C$ untreated, collagen coated stainless steel; $T C$ nitrided, collagen coated stainless steel). Data, normalized with basis on cell proliferation, are expressed as $\mathrm{pg} / \mathrm{ml}$. Each value represents the mean $\pm \mathrm{SD}$ of six separate experiments, each performed in duplicate. $* P<0.01$ (in comparison with $\mathrm{PBMC}$ ); ** $P<0.05$ (in comparison with $\mathrm{PBMC}$ ) ${ }^{\circ} P<0.01$ (in comparison with $\mathrm{S}$ ); ${ }^{\circ} \mathrm{P}<0.05$ (in comparison with $\mathrm{S}$ ) 
Table 2 MMP-9/TIMP-1 ratios

\begin{tabular}{lllll}
\hline PBMC & S & T & SC & TC \\
\hline $1.32 \pm 0.15$ & $1.6 \pm 0.25^{* *}$ & $1.43 \pm 0.15$ & $1.54 \pm 0.20$ & $1.4 \pm 0.19$
\end{tabular}

Values are obtained by dividing each concentration of MMP-9 with corresponding concentration of TIMP-1

** $P<0.05$ (in comparison with PBMC)
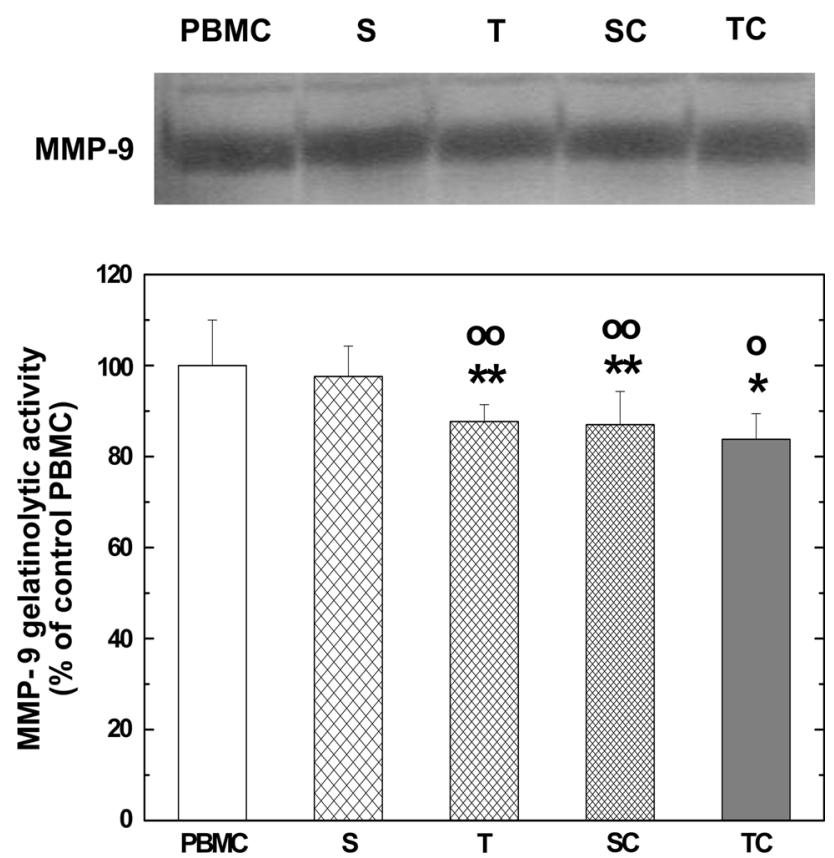

Fig. 7 Effect of AISI 316L stainless steel sample types on gelatinolytic activity of MMP-9 present in the culture medium of PBMC. Cells were maintained in the presence of the complete culture medium alone (PBMC) or put in contact for $48 \mathrm{~h}$ with samples ( $S$ untreated stainless steel; $T$ nitrided stainless steel; $S C$ untreated, collagen coated stainless steel; $T C$ nitrided, collagen coated stainless steel). Top: representative sodium dodecyl sulphate-polyacrylamide gel electrophoresis gelatine zymogram of supernatants of PBMC. The image contrast is depicted in reverse mode such that lysis zones appear as dark bands on light background. Bottom: densitometric analysis of MMP-9, whose levels were normalized on basis on cell proliferation. Data are given relative to control PBMC set equal to 100. Each value represents the mean $\pm \mathrm{SD}$ of six separate experiments, each performed in duplicate. $* P<0.01$ (in comparison with PBMC); ** $P<0.05$ (in comparison with PBMC); ${ }^{\circ} P<0.01$ (in comparison with $\mathrm{S}$ ); ${ }^{\circ} P<0.05$ (in comparison with $\mathrm{S}$ )

samples tested. MMP-9/TIMP-1 ratio is significantly higher in comparison with control PBMC, when the cells were maintained in contact with $\mathrm{S}$ samples (Table 2).

\subsection{Gelatinolytic activity of MMP-9}

The gelatinolytic activity of MMP-9 was determined, by zymography, in the culture medium of PBMC maintained for $48 \mathrm{~h}$ in the absence or in the presence of the studied samples. In Fig. 7 a representative gelatine zymogram is reported (top), together with the densitometric analysis (bottom). PBMC maintained in the presence of the complete culture medium alone were used as control and indicated as PBMC. The densitometric values were calculated as per cent of those of control PBMC. These results are similar to those registered when MMP-9 release was determined, i.e. a slight, but significant decrease in MMP-9 gelatinolytic activity in the presence of all the samples in comparison with control PBMC, with the exception of $\mathrm{S}$ samples. T, SC and TC samples show significant lower MMP-9 gelatinolytic activity in comparison with S.

\section{Discussion}

In this research the effect of AISI $316 \mathrm{~L}$ austenitic stainless steel samples, subjected or not to surface treatments (nitriding and collagen coating procedures), on the biocompatibility of human PBMC was studied.

Low temperature nitriding is particularly useful for increasing the corrosion resistance of austenitic stainless steels in chloride-ion containing solutions [6-9, 13]. This treatment produces a modified surface layer, which consists mainly of S phase. The formation of this phase affects also surface morphology and roughness of the nitrided samples. In fact, the peculiar surface morphology of low temperature glow-discharge nitrided samples is produced not only by plasma etching during sputtering and nitriding, but also by local plastic deformations, due to the high internal stresses caused by nitrogen solubilisation $[6,13,25]$. The high internal stresses may promote also the formation of nitrogen induced h.c.p. martensite, $\varepsilon_{N}$, which is analogous to the strain-induced h.c.p. martensite [6, 13].

As also reported in an our previous paper [13], the modified surface layers significantly increase the corrosion resistance of AISI $316 \mathrm{~L}$ austenitic stainless steel in PBS solution in comparison with the untreated alloy, so higher corrosion potential values and lower passive currents are observed for nitrided samples. This result is supported also by coulimetric zone analysis, which allows to evaluate the degradation due to corrosion phenomena: lower charge values for unit surface occur for nitrided samples in both the chosen potential zones, suggesting a lower degradation of these samples when compared to untreated AISI 316L. 
In the present study, collagen coating was performed on both surface untreated and nitrided samples, without the use of chemical pre-treatments. As previously reported [13], low temperature nitriding treatment promotes a better coating with collagen-I than grinding and polishing procedures alone. It has been reported that preadsorbed proteins, as collagen, laminin and fibronectin, on interfaces may represent a good approach to improve biocompatibility [30-32]. However, in order to assess this improvement, to our opinion, it would be necessary to evaluate other parameters than cell adhesion and proliferation.

Human cell cultures have been widely employed to test biocompatibility. The selection of the cell type plays an important role for cytotoxicity assessment in vitro, and normal cell lines should be preferred to the immortal ones, which may be less sensitive to toxic substances [33, 34]. In particular, human mononuclear cells, a heterogeneous cell population including monocytes and lymphocytes, isolated from heparinised blood, represent a good experimental model to study biocompatibility [35]. For this reason in our research it was chosen to use human PBMC, which were preferred to primary isolated monocytes, due to the difficulties in obtaining sufficient quantities of primary isolated monocytes and to the fact that PBMC reflect a situation similar to that present in vivo. In our study, PBMC response was analyzed after 48-h exposure to the samples or to the culture medium alone, since prolonged incubation may cause nutrient depletion, as also suggested by Catelas et al. [36]. According to Haslam et al. [37], the number of viable animal cells may be based on their LDH activities, so LDH determination is particularly useful for screening potential cell growth inhibitors. The fact that both PBMC proliferation and LDH release were not remarkably affected by the incubation with the metallic samples, if compared with control cells, suggests that cell viability may be considered good. However, if the release of some pro-inflammatory cytokines is taken into account, the conclusion is quite different. Following activation, macrophages secrete an array of inflammatory mediators and a wide range of cytokines [38], as TNF- $\alpha$ and IL-1 $\beta$, which play a crucial role in mediating the infiltration of tissue by leukocytes, via the induction of adhesion molecules on endothelial cells [39]. Therefore, the production of cytokines by blood cells in biocompatibility studies has been widely investigated [40, 41]. Even if Janský et al. [17], who studied the dynamics of cytokine production in human PBMC, reported that many cytokines reach maximal levels after 4 or 12 or $24 \mathrm{~h}$, other authors have chosen to assay cytokine production after longer times of incubation [19]. In our research, cytokine levels were determined after $48 \mathrm{~h}$ of culture, in order to refer the release of the cytokines to PBMC proliferation.
The cytokines assayed by us show different behaviours, according to the observations of Jansky et al. [17], who concluded that the stimulation with different factors may activate the cells of the immune cascade in a different way. Moreover, we have observed that the per cent increase in IL-1 $\beta$ levels in comparison with control PBMC is markedly higher than that showed by TNF- $\alpha$. On the contrary, Bailey et al. [24], utilizing the murine macrophage cell line RAW 264.7, reported that the cells that had phagocytosed AISI $316 \mathrm{~L}$ particles had a nearly three-fold increase in TNF- $\alpha$ expression, and a two-fold increase in IL-1 $\beta$ expression, but cell exposed to nitrogenated stainless steel had a modest increase in TNF- $\alpha$ expression and a four-fold increase in IL- $1 \beta$ expression. This last result is similar to that obtained by us. However, Chang et al. [42] observed that in vitro studies could be easily interfered by cell types, expose time and experimental conditions.

The significant decrease in IL- $1 \beta$ release in the presence of the collagen coated samples (SC and TC), in comparison with the non collagen coated ones, supports our previous observation that also on the surface of the untreated samples a coating of collagen, even if scarce, is present, while the collagen coating of the nitrided samples is not sufficient to completely isolate the metallic surface from the surrounding environment [13].

Upon activation, macrophages secrete both pro-inflammatory cytokines and anti-inflammatory molecules. The most important anti-inflammatory cytokine is IL-10, which inhibits, among the others, TNF- $\alpha$ and IL-12 derived by monocytes/macrophages [43], thus limiting the extent and duration of the inflammatory response. However, low levels of pro-inflammatory cytokines and high levels of anti-inflammatory ones do not always provide an advantage. In fact, in models of localized infections, inhibitors of the pro-inflammatory cytokine system or high concentration of antiinflammatory cytokines may be dangerous to the host, due to the possible invading microbial pathogen [44]. On the other hand, low concentration of anti-inflammatory cytokines leads to an excess of inflammation. Therefore, a right balance between pro-inflammatory and anti-inflammatory cytokines must occur. The secretion of IL-10 is stimulated by proinflammatory cytokines, as TNF- $\alpha$ [45]. In our study, even if a significant increase in IL-10 release by PBMC, put in contact with T or TC samples, was registered, TNF- $\alpha$ levels were high and almost unchanged in the presence of all the samples. It is possible that, after 48-h incubation, the increase in IL-10 levels is not so marked to counteract the release of pro-inflammatory cytokines. In fact, Chang et al. [19] demonstrated that IL-10 generally increases over the 10-day cultures, suggesting the damping of the immune response after 10 days. Also Gretzer et al. [45] found differences in IL-10 secretion, and suggested that the materials evoke different kinetics of cytokine secretion. 
In order to understand how ECM remodelling occurs, it is important to study the secretion of MMPs and of their specific inhibitors, TIMPs. TIMPs bind MMPs in a 1:1 stoichiometric ratio [46], and the balance between MMPs and TIMPs determines the degradative state of the extracellular matrix. MMP-9 is a member of the great family of matrix-metabolizing enzymes, which act as mediators of tissue remodelling also during pathological processes [47], and it is now considered an example of the regulation of immune functions by proteolysis. MMP-9, that is expressed by many cell types, and also by PBMC, plays a key role during inflammation, and, in fact, it can be induced by pro-inflammatory cytokines, as TNF- $\alpha$ and IL- $1 \beta$, while its production is inhibited by IL-10. In our research, MMP-9 did not increase in the presence of the metallic samples. It may be supposed that IL-10 levels, even not so high, inhibit the production of MMP-9, which, on the other hand, is not affected by the increased concentration of TNF- $\alpha$. It is noteworthy that also the gelatinolytic activity of MMP-9 shows the same trend observed when MMP-9 release was determined.

In chronic inflammation, it is desired that the biological activities of MMPs are inhibited by TIMPs. Even if TIMPs do not show specificity for any particular MMP, it has been observed that TIMP-1 prefers MMP-9. Although TIMP-1 expression is induced by many stimuli, among which proinflammatory cytokines [48], we have not registered the expected increase in TIMP-1 levels. If we consider MMP9/TIMP-1 ratio, the better value was obtained in the presence of TC samples. This result is, to our opinion, very important, as it demonstrates that not only MMP-2, produced by endothelial cells (HUVEC), is not affected by the nitrided and collagen coated samples, as previously reported [13], but the same trend is also registered for MMP9 released by PBMC.

\section{Conclusions}

Low temperature nitriding, performed at $400{ }^{\circ} \mathrm{C}, 500 \mathrm{~Pa}$, for $5 \mathrm{~h}$ with the glow-discharge technique, produces, on AISI 316L austenitic stainless steel, modified surface layers, consisting mainly of $\mathrm{S}$ phase. These modified layers show an improved corrosion resistance in PBS aerated solution, when compared to the untreated alloy.

Biocompatibility studies, carried out in vitro using human PBMC, show that proliferation, viability and MMP-9 secretion are not negatively affected by the contact with all the AISI 316L samples subjected or not to nitriding and/or collagen coating. On the other hand, when the secretion of some pro-inflammatory cytokines is considered, a remarkable increase is always registered in comparison with control cells. However, in the presence of nitrided and collagen coated samples a significant decrease in the secretion of the pro-inflammatory cytokine IL-1 $\beta$ and an increase in that of the anti-inflammatory cytokine IL-10 are observed in comparison with untreated AISI 316L.

Thus, taking into account the results of the present study and those previously obtained using endothelial cells (HUVEC), it may be suggested that, when AISI 316L austenitic stainless steel is subjected to low temperature nitriding, followed by a collagen coating, some biological parameters are ameliorated.

Moreover, our study suggests that, when cells in culture are used to evaluate biocompatibility, cell proliferation and viability alone may be not sufficient to assess the result, but the determination of factors related with inflammatory processes should also be considered.

Acknowledgments This study was supported by grants from MIUR (Ministero dell'Istruzione, dell'Università e della Ricerca) and by a donation of Ente Cassa di Risparmio di Firenze.

\section{References}

1. Wapner KL. Implications of metallic corrosion in total knee arthroplasty. Clin Orthop Relat Res. 1991;271:12-20.

2. Hallab N, Merritt K, Jacobs JJ. Metal sensitivity in patients with orthopaedic implants. J Bone Joint Surg Am. 2001;83(A):428-36.

3. Hallab N, Link HD, McAfee PC. Biomaterial optimization in total disc arthroplasty. Spine. 2003;28:139-52.

4. Bertrand OF, Sipehia R, Mongrain R, Rodes J, Tardif JC, Bilofdeau L, Cote G, Bourassa MG. Biocompatibility aspects of new stent technology. J Am Coll Cardiol. 1998;32:562-71.

5. Jacobs AM, Gloff LM. Podiatric metallurgy and the effects of implanted metals on living tissues. Clin Podiatry. 1985;2:121-41.

6. Fossati A, Galvanetto E, Bacci T, Borgioli F. Improvement of corrosion resistance of austenitic stainless steels by means of glow-discharge nitriding. Corros Rev. 2011;29:209-21.

7. Martinesi M, Bruni S, Stio M, Treves C, Bacci T, Borgioli F. Biocompatibility evaluation of surface-treated AISI 316L austenitic stainless steel in human cell cultures. J Biomed Mat Res A. 2006;80A:131-45.

8. Buhagiar J, Dong H. Corrosion properties of S-phase layers formed on medical grade austenitic stainless steel. J Mater Sci Mater Med. 2012;23:271-81.

9. Dong H. S-phase surface engineering of $\mathrm{Fe}-\mathrm{Cr}, \mathrm{Co}-\mathrm{C}$ and $\mathrm{Ni}-\mathrm{Cr}$ alloys. Int Mater Rev. 2010;55:65-98.

10. Buhagiar J, Bell T, Sammons R, Dong H. Evaluation of the biocompatibility of S-phase layers on medical grade austenitic stainless steels. J Mater Sci Mater Med. 2011;22:1269-78.

11. Lin Y-H, Lan W-C, Ou K-L, Liu C-M, Peng P-W. Hemocompatibility evaluation of plasma-nitrided austenitic stainless steels at low temperature. Surf Coat Technol. 2012;206:4785-90.

12. Hauser J, Koeller M, Bensch S, Halfmann H, Awakowicz P, Steinau H-U, Esenwein S. Plasma mediated collagen-I-coating of metal implant materials to improve biocompatibility. J Biomed Mater Res A. 2010;94A:12-26.

13. Martinesi M, Stio M, Treves C, Borgioli F. Biocompatibility studies of low temperature nitrided and collagen-I coated AISI 316L austenitic stainless steel. J Mater Sci Mater Med. 2013;24:1501-13.

14. Chen J, Chen C, Chen Z, Chen J, Li Q, Huang N. Collagen/heparin coating on titanium surface improves the biocompatibility of titanium applied as a blood-contacting biomaterial. J Biomed Mater Res A. 2010;95A:341-9. 
15. Thomsen P, Gretzer C. Macrophage interactions with modified material surfaces. Curr Opin Solid State Mater. 2001;5:163-76.

16. Santin M, Mikhalovska L, Lloyd AW, Mikhalovsky S. In vitro host response assessment of biomaterials for cardiovascular stent manufacture. J Mat Sci: Mater Med. 2004;15:473-7.

17. Janský L, Reymanová P, Kopecký J. Dynamics of cytokine production in human peripheral blood mononuclear cells stimulated by LPS or infected by Borrelia. Physiol Res. 2003;52:593-8.

18. Schildberger A, Rossmanith E, Eichhorn T, Sttrassl K, Weber V. Monocytes, peripheral blood mononuclear cells, and THP-1 cells exhibit different cytokine expression patterns following stimulation with Lipopolysaccharide. Mediators of Inflammation. 2013;2013:Art. ID 697972.

19. Chang DT, Jones JA, Meyerson H, Colton E, Kwon IK, Matsuda T, Anderson JM. Lymphocyte/macrophage interactions: biomaterial surface-dependent cytokine, chemokine, and matrix protein production. J Biomed Mater Res A. 2008;87A:676-87.

20. Jones JA, McNally AK, Chang DT, Qin LA, Meyerson H, Colton E, Kwon ILK, Matsuda T, Anderson JM. Matrix metalloproteinases and their inhibitors in the foreign body reaction on biomaterials. J Biomed Mater Res A. 2008;84A:158-66.

21. Sternlicht M, Werb Z. How matrix metalloproteinases regulate cell behavior. Annu Rev Cell Dev Biol. 2001;17:463-516.

22. Newby A. Matrix metalloproteinases regulate migration, proliferation, and death of vascular smooth muscle cells by degrading matrix and non-matrix substrates. Cardiovasc Res. 2006;69:614-24.

23. Horowitz SM, Doty SB, Lane JM, Burstein AH. Studies of the mechanism by which the mechanical failure of polymethylmethacrylate leads to bone resorption. J Bone Joint Surg Am. 1993;75:802-13.

24. Bailey LAO, Lippiatt S, Biancanello FS, Ridder SD, Washburn NR. The quantification of cellular viability and inflammatory response to stainless steel alloys. Biomaterials. 2005;26:5296-302.

25. Borgioli F, Fossati A, Galvanetto E, Bacci T, Pradelli G. Glow discharge nitriding of AISI 316L austenitic stainless steel: influence of treatment pressure. Surf Coat Technol. 2006;200:5505-13.

26. Reclaru L, Meyer J-M. Zonal coulimetric analysis of the corrosion resistance of dental alloys. J Dent. 1995;23:301-11.

27. Reclaru L, Ziegenhagen R, Eschler P-Y, Blatter A, Lemaître J. Comparative corrosion study of "Ni-free" austenitic stainless steels in view of medical applications. Acta Biomater. 2006;2:433-44.

28. Eisenbarth E, Velten D, Müller M, Thull R, Breme J. Biocompatibility of $\beta$-stabilizing elements of titanium alloys. Biomaterials. 2004;25:5705-13.

29. Rosenbloom SN, Corbett R. An assessment of ASTM F 2129 electrochemical testing of small medical implants-lessons learned. In: Proc NACE Corrosion 2007 Conference and Expo, Houston, TX, 2007, paper 07674.

30. Stadlinger B, Pilling E, Mai R, Bierbaum S, Berhardt R, Scharnweber D, Eckelt U. Effect of biological implant surface coatings on bone formation, applying collagen, proteoglycans, glycosaminoglycans and growth factors. J Mater Sci Mater Med. 2008;19:1043-9.

31. Rammelt S, Illert T, Bierbaum S, Scharnweber D, Zwipp H, Schneiders W. Coating of titanium implants with collagen, RGD peptide and chondroitin sulphate. Biomaterials. 2006;27:5561-71.
32. Rammelt S, Schulze E, Bernhardt R, Hanisch U, Scharnweber D, Worch H, Zwipp H, Biewener A. Coating of titanium implants with type-I collagen. J Orthop Res. 2004;22:1025-34.

33. Rach J, Halter B, Aufderheide M. Importance of material evaluation prior to the construction of devices for in vitro techniques. Exper Toxicol Pathol. 2013;65:973-8.

34. Kirkpatrick CJ, Peters K, Hermanns MI, Bittinger F, KrumpKonvalinkova V, Fuchs $S$, et al. In vitro methodologies to evaluate biocompatibility: status quo and perspective. ITBM-RBM. 2005;26:192-9.

35. Anderson JM, Rodriguez A, Chang DT. Foreign body reaction to biomaterials. Semin Immunol. 2008;20:86-100.

36. Catelas I, Petit A, Zukor DJ, Antoniou J, Huk OL. TNF- $\alpha$ secretion and macrophage mortality induced by cobalt and chromium ions in vitro-Qualitative analysis of apoptosis. Biomaterials. 2003;24:383-91.

37. Haslam G, Wyatt D, Kitos PA. Estimating the number of viable animal cells in multi-well cultures based on their lactate dehydrogenase activities. Cytotechnology. 2000;32:63-75.

38. Fujiwara N, Kobayashi K. Macrophages in inflammation. Curr Drug Targets Inflamm Allergy. 2005;4:281-6.

39. Sternberg Z, Chadha K, Lieberman A, Hojnacki D, Drake A, Zamboni P, Rocco P, Grazioli E, Weinstock-Guttman B, Munschauer F. Quercetin and interferon- $\beta$ modulate immune response(s) in peripheral blood mononuclear cells isolated from multiple sclerosis patients. J Neuroimmunol. 2008;205:142-7.

40. Suska F, Gretzer C, Esposito M, Tengvall P, Thomsen P. Monocyte viability on titanium and copper coated titanium. Biomaterials. 2005;26:5942-50.

41. Trindade MCD, Lind M, Sun D, Schurman DJ, Goodman SB, Smith RL. In vitro reaction to orthopaedic biomaterials by macrophages and lymphocytes isolated from patients undergoing revision surgery. Biomaterials. 2001;22:253-9.

42. Chang JS, Chang KL, Hwang DF, Kong ZL. In vitro cytotoxicity of silica nanoparticles at high concentrations strongly depends on the metabolic activity type of the cell line. Environ Sci Technol. 2007;41:2064-8.

43. Opal SM, DePalo VA. Anti-inflammatory cytokines. CHEST. 2000;117:1162-72.

44. Opal SM, Wherry JC, Grint P. Interleukin-10: potential benefits and possible risks in clinical infectious diseases. Clin Infect Dis. 1998;27:1497-507.

45. Gretzer C, Gisselfält K, Liljensten E, Rydén L, Thomsen P. Adhesion, apoptosis and cytokine release of human mononuclear cells cultured on degradable poly(urethane urea), polystyrene and titanium in vitro. Biomaterials. 2003;24:2843-52.

46. Visse R, Nagase H. Matrix metalloproteinases and tissue inhibitors of metalloproteinases: structure, function, and biochemistry. Circ Res. 2003;92:827-39.

47. Opdenakker G, Van den Stehen PE, Van Damme J. Gelatinase B: a tuner and amplifier of immune functions. Trends Immunol. 2001;22:571-9.

48. Li YY, McTiernan CF, Feldman AM. Proinflammatoty cytokines regulate tissue inhibitors of metalloproteinases and disintegrin metalloproteinase in cardiac cells. Cardiovasc Res. 1999;42:162-72. 